\title{
Knowledge, Attitude and Practice of Primary Health Care Physicians regarding Cupping (Hijama) in Primary Health Care Centers in Port-Said City
}

\author{
Reham M. Abo Omara, Nahed Eldahshan *, Nadia Mabrouk
}

Department of Family Medicine, Faculty of Medicine, Suez Canal University, Egypt

\begin{abstract}
Background: Complementary and Alternative Medicine (CAM) encompasses all forms of therapies that fall outside the mainstream of medical practice. Cupping is among known items of alternative medicine assigned by the WHO and highlighted recently. The role of cupping in cure of many known disease was addressed as one of the main methods of treatment in the prophet medicine. Aim: To improve primary health care physicians' quality of care for patients. Objectives: To determine the level of knowledge, attitude, and practice of PHC physicians regarding cupping. Subjects and Methods: It is a cross sectional descriptive study, which was carried out in PHC centers in Port said city. Sixty-one PHC Phs were included in the study. Their knowledge, attitude and practices cupping were assessed. Structured questionnaire was used in the interview with physicians. Obtained data were entered and analyzed using Statistical Package of Social Science (SPSS 20). The appropriate statistical tests were used. Statistical significance was considered at p-value $<0.05$. Results: The current study showed that a considerable percent $(52.5 \%)$ of the studied group did not pass knowledge score regarding cupping. About (47.5\%) of the studied group have favorable attitude. As regards practices of PHC physicians regarding cupping, it was evident that no one of the studied group practiced cupping before. Conclusion: The current study concluded that the level of knowledge, attitude, and practice of PHC physicians regarding cupping was unsatisfactory. Scientific intervention on cupping to prove its efficacy, safety and quality and more training programs also needed.
\end{abstract}

Key words: CAM; cure; prophet medicine.

\section{Introduction}

Despite the fact that for years traditional practice received relatively little support from national and international health organizations, they have survived and their influence on health care system have been recognized. In the 21st century, the world health organization (WHO) has supported the integration of conventional and alternative medicine to improve the quality of health care $^{(1)}$. About $80 \%$ of people in Africa use traditional medicine, while in developed countries a growing number of patients rely on alternative medicine for preventive or palliative care. In France, $75 \%$ of the population has used complementary medicine at least once; in Germany, $77 \%$ of pain clinics provide acupuncture; and in the united kingdom, expenditure on complementary or alternative medicine stands at $\$ 2300$ million per

*Corresponding Author: nahed.eldahshan@yahoo.com 
year ${ }^{(2)}$. Cupping is among known items of alternative medicine assigned by the WHO and highlighted recently. the role of cupping in cure of many known disease was addressed and stressed upon as one of the main methods of treatment in the prophet medicine ${ }^{(3)}$ and is now very popular in Europe ${ }^{(4)}$. It has been reported that around $50 \%$ of the people in the western countries take daily one or more of conventional medicines, however many patient who take medical treatment suffer from their side effects, toxicity and psychic stresses which make them stop their medication. Moreover, those patients, their families, and the government suffer from the economic burden of making the drugs available, which may need to spend of hard currency by the government. So the traditional or alternative medicine including cupping increases the attention of the industrialized world and many of the developing countries to avoid all the previous hazards of the chemical drugs ${ }^{(2)}$. Many studies ${ }^{(5-6)}$ examined the effect of cupping for low back pain, chronic headache, migraine, knee pain, chronic asthmatic bronchitis and rheumatoid arthritis and revealed the great efficacy of cupping in treating such diseases. Although the role of cupping is known and practiced in many developed and developing countries including many Arab countries, many of the mass media tackled this role ,yet many of our physicians are either refusing this role, or having very superficial idea about this subject ${ }^{(7)}$. In addition, there is distinct lack of knowledge about this subject by many physicians. Cupping is simple, inexpensive and unsophisticated method could be more frequently and effectively be put into practice ${ }^{(8)}$. Discussion around cupping has and broadcasting channels and even among the highest medical levels. Some people accept cupping as a kind of alternative medicine, others refuse and some are just watching what is happening and do not know what is right. Some researches proved that cupping cures many of the disease in which modern medicine fails. The groups who refuse cupping see it as quack's remedy or as an old, traditional and folkloric method of treatment that cannot be accepted in these days of great scientific development ${ }^{(7)}$.

\section{Subjects and Methods}

The current study is a cross sectional descriptive one that was conducted from February 2012 to March 2013. It was carried out in PHC (primary health care) centers in Port Said city included 9 PHC centers. Sixty-one $\mathrm{PHC}$ physicians those working in these PHC centers were included in the study. A structured questionnaire was developed by the researcher revised by the supervisors and validated according to pilot study on $10 \mathrm{FPhs}$ and expert physician at pain clinic in Suez Canal university hospital to assess the ease of comprehension, relevance to the intended topics and the degree to which the questions are interpreted and understood by different physicians. Interviews were done with the working PHC physicians $^{(10)}$ using the developed questionnaire. The questionnaire is composed of two parts: Part one, contained some selected demographic variables as (gender, age, Qualification and experience years in family medicine), in addition to one question regarding their sources of cupping knowledge. Part 2 included multiplechoice questions for assessing knowledge, attitude, and practice of $\mathrm{PHC}$ physicians regarding cupping. Knowledge score was not passed knowledge if $<50 \%$, and passed know-ledge if $\geq 50 \%$. Attitude score was favorable attitude if $\geq 70 \%$ and unfavorable attitude if $<70 \%$. Practice 
score was appropriate if $\geq 60 \%$ and inappropriate if $<60 \%$, these cut off points are according to the mean of the answers.

\section{Statistical Analysis}

The obtained data were analyzed using Statistical Package of Social Science (SPSS) version 20. The appropriate statistical tests were used to identify significant difference. Chi square test and Fisher Exact test were used for categorical data. Test of significance was conducted to find the relations between total score of knowledge, attitude and practice versus different demographic variables and the correlation of knowledge and the attitude. Statistical significance was considered at $\mathrm{p}$-value $<0.05$.

\section{Results}

This study included 61 PHC physicians in 9 PHC centers in port-Said city. Physicians with experience $<5$ years

Table 1: Socio- demographic characteristics of the Primary health care physicians

\begin{tabular}{|c|c|}
\hline $\begin{array}{c}\text { Characteristics } \\
\text { Male }\end{array}$ & No (\%) \\
Female & $16(62.2 \%)$ \\
\hline Age & $45(73.8 \%)$ \\
$25-30$ years & $37(60.7 \%)$ \\
30-40years & $21(34.4 \%)$ \\
$\geq 40 y e a r s$ & $3(4.9 \%)$ \\
\hline Qualifications & \\
(Educational level) & \\
Bachelor & $29(75.4 \%)$ \\
Diploma & $13(21.3 \%)$ \\
Master & $19(3.3 \%)$ \\
\hline Experience in & \\
family medicine & \\
$<5$ yrs & $37(60.7 \%)$ \\
$\geq 5$ years & $24(39.3 \%)$ \\
\hline
\end{tabular}

It was obvious that more than two thirds of participants were females accounting for (73.8\%) participants. About one third (31. 1\%) were master (qualified) physicians.
Physicians with experience $<5$ years in family medicine constituted the majority of the sample (60.7\%). About two third $(60.7 \%)$ of the sample were $<30$ years old (Table 1). Figure (1) Illustrates that more than half $(52.5 \%)$ of the studied PHC physicians have poor knowledge score regarding cupping. The majority (52.5\%) of the studied PHC physicians have unfavorable attitude regarding cupping (Hijama) (Figure 2). None of the studied PHC physicians (100\%) practiced cupping before. The PHC physicians' know-ledge score regarding cupping in relation to their characteristics is shown in table (2). It was obvious that (75\%) of physicians who had poor knowledge were non-qualified. The relation was statistically significant $P$ $<0.05$. Majority of PHC physicians did not pass the knowledge evaluation (68.8\%) were less than 30 years old. The relation was statistically significant $P<0.05$. Also most of studied group of physicians who have poor knowledge regarding cupping had experience less than 5years in their work The relation was statistically significant $\mathrm{P}<0.05$. Table (3) shows $\mathrm{PHC}$ physicians' attitude score regarding cupping in relation to their characteristics. It was obvious that there was no statistically significant $(P<0.05)$ relation between attitude score and their socio-demographic characteristics. Figure (3) Scatter/dot graph demonstrates the correlation between knowledge score and attitude score. There was a positive significant correlation between knowl-edge and attitude scores ( $p<0.05$ ). Figure (4) illustrates the distribution of PHC physicians regarding their sources of information regarding cupping. Radio and Television accounts the majority (41\%), friends and neighbors (39.3\%), courses and workshops (38\%), internet (29.5\%) and the least were medical books ( $4.9 \%)$. These were the commonest sources for cupping information. 

Table 2: Relation between socio-demographic characteristics of primary health care physicians and their knowledge score regarding cupping (Hijama)

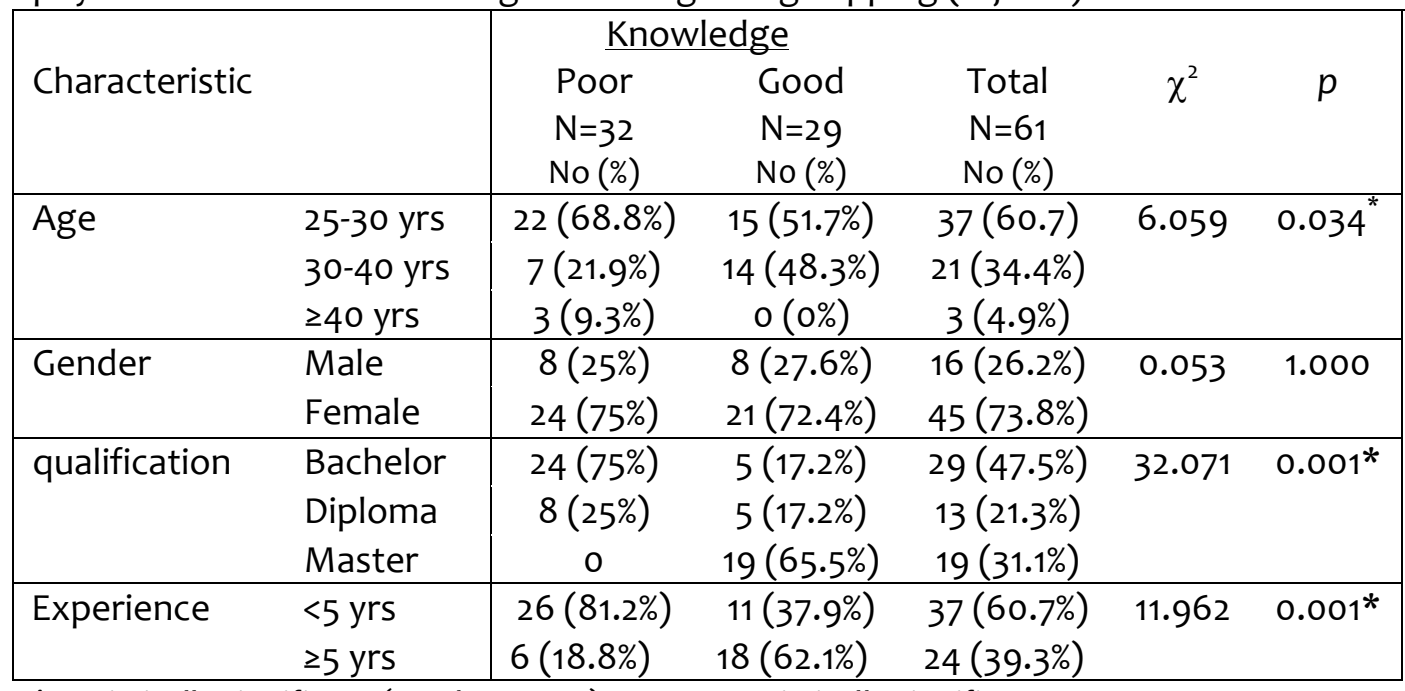

*Statistically significant (P-value <0.05) NS: not statistically significant

Table 3: Relation between socio-demographic characteristics of primary health care physicians and their attitude score regarding cupping (Hijama)

\begin{tabular}{|c|c|c|c|c|c|}
\hline \multirow[t]{3}{*}{ Characteristic } & \multicolumn{2}{|c|}{ Attitude } & \multirow[b]{2}{*}{$\begin{array}{l}\text { Total } \\
(\mathrm{N}=61)\end{array}$} & \multirow[b]{3}{*}{$\chi^{2}$} & \multirow[b]{3}{*}{ p-value } \\
\hline & $\begin{array}{c}\text { Favorable } \\
(\mathrm{N}=29)\end{array}$ & $\begin{array}{c}\text { Unfavorable } \\
(\mathrm{N}=32)\end{array}$ & & & \\
\hline & No (\%) & No (\%) & No (\%) & & \\
\hline Age & & & & 1.005 & 0.617 \\
\hline $25-<30$ yrs & $16(55.2 \%)$ & $21(65.6 \%)$ & 37 (60.7\% & & \\
\hline $30-<40$ yrs & $11(37.9 \%)$ & $10(31.2 \%)$ & $21(34.4 \%)$ & & \\
\hline$\geq 40 \mathrm{yrs}$ & $2(6.9 \%)$ & $2(6.9 \%)$ & $3(4.9 \%)$ & & \\
\hline Gender & & & & .660 & 0.562 \\
\hline Male & $9(31 \%)$ & $7(21.9 \%)$ & $16(26.2 \%)$ & & \\
\hline Female & $20(69 \%)$ & $25(78.1 \%)$ & $45(73.8 \%)$ & & \\
\hline qualification & & & & 5.314 & 0.068 \\
\hline Bachelor & $10(35.5 \%)$ & $19(59.4 \%)$ & $29(47.5 \%)$ & & \\
\hline Diploma & $6(20.7 \%)$ & $7(21.9 \%)$ & $13(21.3 \%)$ & & \\
\hline Master & $13(44.8 \%)$ & $6(18.8 \%)$ & $19(31.1 \%)$ & & \\
\hline Experience & & & & 0.096 & 0.798 \\
\hline$<5$ yrs & $17(58.2 \%)$ & $20(62.5 \%)$ & $37(60.7 \%)$ & & \\
\hline$\geq 5 \mathrm{yrs}$ & $12(41.4 \%)$ & $12(37.5 \%)$ & $24(39.3 \%)$ & & \\
\hline
\end{tabular}

*statistically significant (P-value $<0.05)$ NS: not statistically significant

\section{Discussion}

The present descriptive study was carried out on 61 primary health care physicians working at primary health care centers (PHCS) in Port-Said city. The study aimed to improve knowledge, attitude, and practice of the PHCs regarding cupping. Physicians working in primary health care centers fulfilled a written questionnaire. Out of $61 \mathrm{PHCs}$, more than two-thirds (73.8\%) were females, about two third (60.7\%) of the sample were less than thirty years old, about one third (31.1\%) had master degree (qualified). 


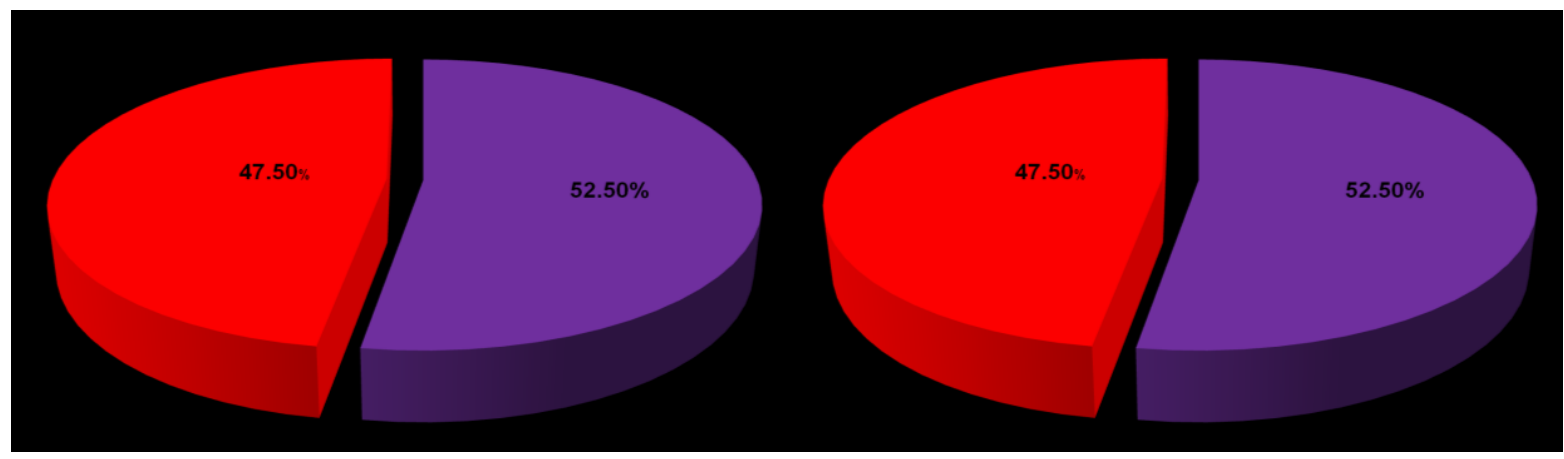

Figure 1: physicians' score in knowledge assessment regarding cupping (hijama).
Figure 2: physicians' score in attitude assessment regarding cupping.
Physicians with experience less than 5 years in family medicine constituted the majority of the sample (60.7\%). This is inconsistent with a study conducted in Korea in 2002 about knowledge, attitudes, and practice of complementary and alternative medicine among oriental medicine-trained physicians. The Korean study showed a mean age of physicians of 39.9 years. The number of male practitioners was significantly higher than the number of female practitioners among the studied group, and the average years of experience was 12 years ${ }^{(10)}$. The current study showed that more than half $(52.5 \%)$ of the study physicians had poor knowledge regarding cupping (score less than 50\%). This may not be surprising, given that many of the respondents went through medical school and residency at a time when complementary and alternative medicine (CAM) (cupping is one of them) was not widely discussed and rarely included in medical school curriculums. This may explain the low level of knowledge found among the participants in the study. In partial agreement with this study, a study conducted in Cairo University in 2006 to assess the knowledge, attitude and practice regarding cupping among medical staff and reported that $76.5 \%$ had got a score less than (50\%). This indicates that the knowledge of the medical staff of this study about cupping was very low ${ }^{(11)}$ compared to the knowledge score of the studied group of physicians. This could be explained by the fact that about $36 \%$ of them had attended courses and workshops in family medicine department at Suez Canal University. The current study showed that about $47.5 \%$ had favorable attitude and accepted it as a method of treatment. In addition, the majority agreed upon introduction of cupping in the curriculum of faculty of medicine. This was consistent with a study conducted in Tehran in which the overall physicians had positive attitudes toward usefulness of complementary methods, however, they needed to improve their knowledge on this topic ${ }^{(12)}$. This is inconsistent with study done at Cairo University in 2006, which demonstrated that less than 30\% accept cupping as a method of treatment, while more than $70 \%$ encourages the introduction of cupping in the curriculum of faculties of medicine as a scientific issue. This indicates that the group who refuse cupping now as a method of treatment may use it one day as a modality of treatment if they got enough information about it and if it has been taught in the faculties of medicine as a scientific issue ${ }^{(13)}$. The current 
study showed that about $47.5 \%$ had favorable attitude and accepted it as a method of treatment. In addition, the majority agreed upon introduction of cupping in the curriculum of faculty of medicine. This was consistent with a study conducted in Tehran in which the overall physicians had positive attitudes toward usefulness of complementary methods, however, they needed to improve their knowledge on this topic ${ }^{(12)}$. This is inconsistent with study done at Cairo University in 2006, which demonstrated that less than $30 \%$ accept cupping as a method of treatment, while more than $70 \%$ encourages the introduction of cupping in the curriculum of faculties of medicine as a scientific issue. This indicates that the group who refuse cupping now as a method of treatment may use it one day as a modality of treatment if they got enough information about it and if it has been taught in the faculties of medicine as a scientific issue ${ }^{(13)}$. Surprisingly, in the current study no one of the studied physicians had

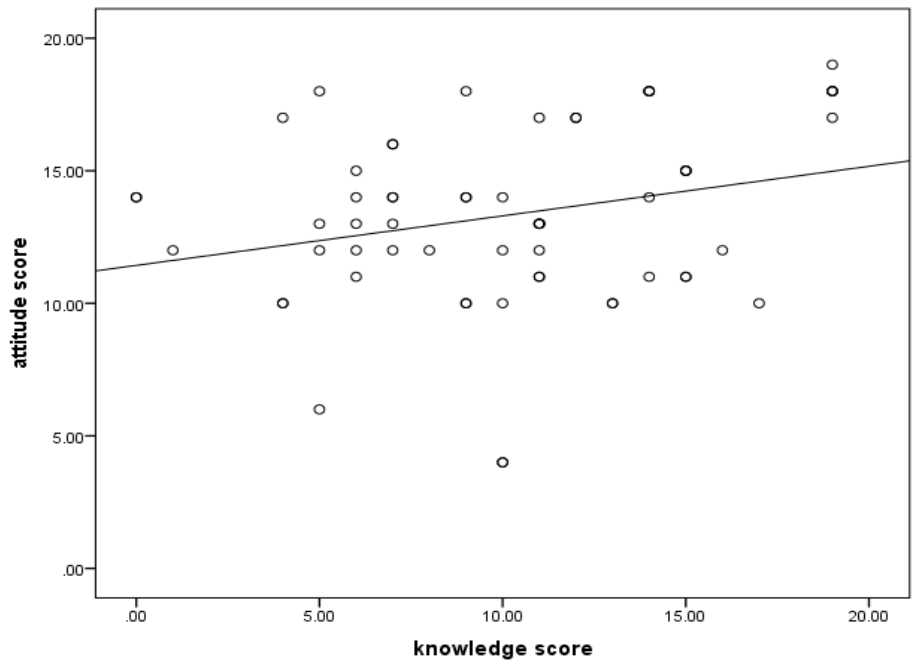

Figure 3: Scatter/dot graph shows the correlation between knowledge score and attitude score $(r=0.267$, $\mathrm{p}=0.038$ ).

practiced cupping before. In similar results of a study of Cairo university in 2006 only (1\%) practiced cupping for others. This may be attributed to absence of specific CAM centers in Egypt and in addition to the lack of knowledge and training of physicians in CAM, this is in contrary to results of a study in Tehran, showing that There were at least $9.9 \%$ of physicians using one or more methods of complementary medicine in practice and $24 \%$ of them had referred their patients to alternative therapist during the last 6 months ${ }^{(12)}$. Many countries had integrated the alternative medicine in their policies. There are hospitals for alternative medicine in Britain, which follow the general health sector, Kuwait had integrated the alternative medicine in its policies in 1984, United Arab Emirates in 2002 specified an office for registration, interviewing and giving license for those who practice alternative medicine. In addition, Jordon and Iran agreed to integrate the complementary medicine in their health and education systems. However, Egypt was one of the countries that didn't integrate the alternative medicine in its health system up till now $^{(14)}$. A study was conducted by Hasan et al. $(2000)^{(15)}$ to explore the attitudes and practices of general practitioners and medical students in the United Arab Emirates with regards the forms of therapy. The results showed the widespread use of alternative medicine among students, GPs, and their friends and relatives. 


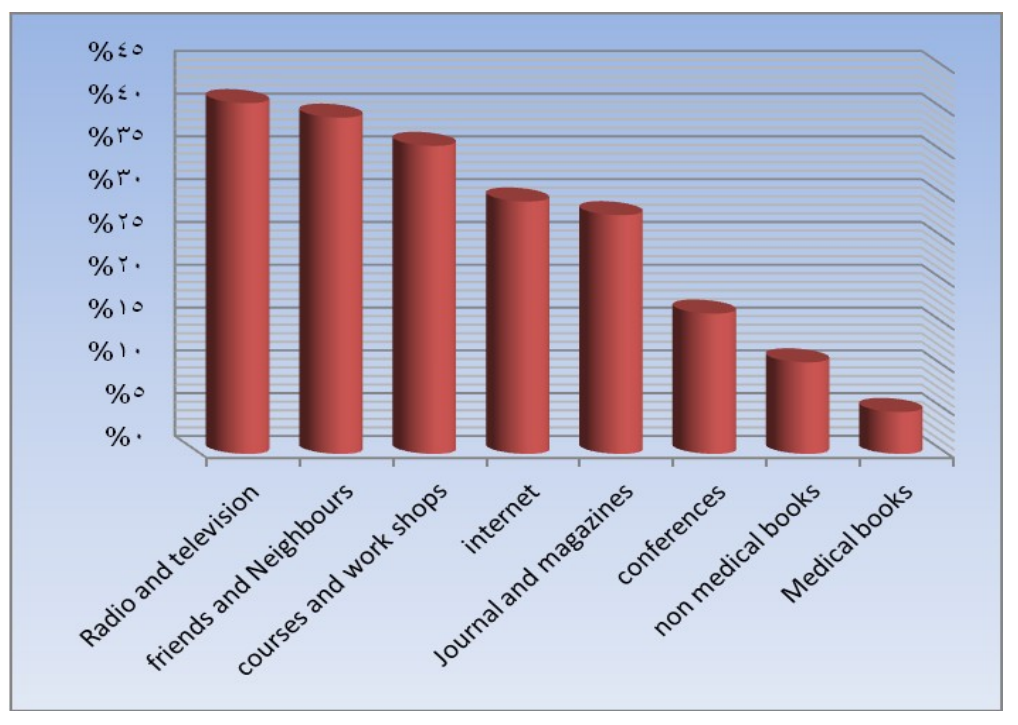

Figure 4 Primary health care physicians' sources of information regarding cupping (Hijama) (NB: responders have mentioned one or more sources for their information about cupping).
Another study examined by Andrew and Anna (2005) ${ }^{(16)}$ the use of complementary and alternative medicine (CAM) therapies among Chinese and Vietnamese Americans. The results showed that the use of CAM therapies was common among Chinese and Vietnamese Americans By studying some factors affecting the results (passed or not passed) of PHCs found that qualification was the main factor significantly affecting their knowledge results $(P<0.05)$. It was obvious that $(75 \%)$ of physicians who have poor knowledge evaluation were non-qualified. Also there was significant relation( $p<0.001)$ between knowledge score and experience as most of studied group( $81.2 \%$ ) of physicians who had poor knowledge regarding cupping had experience less than 5 years in their work. There was no significant relation between gender and knowledge sore in this study. This is consistent with the study conducted in Cairo University $\mathbf{2 0 0 6}$, as there was no significant difference between male and female staffs as regards score of knowledge. That is because those males and females were of the same educational level, same social class, and work in the same field ${ }^{(13)}$. The current study showed no statistically sig- nificant relation between the attitudes of physicians and their socio-demographic characteristics. Inconsistent with our study, Previous studies showed that certain demographic factors such as age, sex, ethnicity, practice type and location of medical training; had significant effect on physicians' attitudes ${ }^{(17-19)}$. In addition, current study showed positive significant correlation between knowledge and attitude scores $(p<0.05)$. One explanation is that improved knowledge may motivate the studied group to change their attitude regarding cupping either by acceptance cupping as method of treatment or by counseling about using cupping as a method of treatment in PHC and motivate them to improve their current knowledge regarding this issue. The current study showed that Radio and Television account the majority (41\%), friends and neighbors (39.3\%), courses and workshops (38\%), internet (29.5\%) and the least were medical books (4.9\%). This is similar to the study of Cairo University 2006, which demonstrates that friends represented the most important source of information about cupping. However, the medical books represented the least source of information. This indicates that 
the issue of alternative medicine especially cupping is ignored as a scientific issue that should be tackled in our researches as the conventional medicine. The reasons behind why the medical books represented the least source of information to the medical staff may be the nonavailability of such books according to the evidence-based medicine that tackle the alternative medicine issue and that the alternative medicine is not integrated in our health system policy in Egypt. Although the WHO today had released a global plan to address issues about alternative medicine and its strategy provides a framework for policy to assist countries to regulate traditional or complementary/ alternative medicine (TM/CAM) to make its use safer, more accessible to their populations and sustainable ${ }^{(20)}$. On the contrary the alternative medicine including cupping is not tackled in our medical books. In-spite more than $80 \%$ of the developing world's population still depends on the complementary and alternative systems of medicine, while about half of the population in industrialized countries uses ${ }^{(21)}$, yet the alternative medicine including cupping is not integrated in our health system and not considered in our medical books. In addition, the Alma-Ata declaration in 1978 particularly said that mobilization of traditional medicine systems is an important way to make health for all a reality ${ }^{(22)}$. Upon reviewing previous studies worldwide regarding CAM practice, it was found that $73 \%$ of Japanese and $85 \%$ of Germans practiced CAM before (mostly herbal medicine and homeopathy). Another study by Haselen and co-workers $(2004)^{(23)}$ to assess primary care health professionals' perceptions of need and of some ways to integrate CAM in primary care in Northwest London. The results showed a considerable interest in CAM among primary care professionals, and many are already referring or suggesting referral for CAM treatments. Such referrals are driven mainly by patient demand (68\%), and by dissatisfaction with the results of conventional medicine (58\%). Most of the respondents were in favor of integrating at least some types of CAM in mainstream primary care. There is an urgent need to further educate/inform primary care health professionals about CAM. From all the previous studies it is apparent that the alternative medicine (cupping is one of them) is well known in United Arab Emirates, China, America and Britain. On the contrary, cupping is ignored and not yet formally accepted as a method of treatment by the health authorities in Egypt. The variations between countries regarding the familiarity of physicians to different CAM therapies, their attitude, practice pattern and referral rates is explained by the cultural and geographical differences and beliefs; however, such difference is significant and indicates the need of regional studies before designing educational programs and making decisions about the reform of health care system.

\section{Conclusion}

This study has explored several aspects of cupping related KAP of PHC Physicians. It has identified the need for improvement in their knowledge consequently their practice regarding cupping. It is thus recommended that doing more scientific researches on cupping to prove its efficacy, safety, quality, and more training programs also needed to PHC Physicians in CAM modalities and its uses in order to deliver better quality of patient care.

Study limitations

Daily duties of PHC physicians interfered with evaluation of physicians in the same day, so we divided them into 3 groups (10 
physicians per week), coming to the PHC centers to set for evaluation and collection of answers.

\section{Acknowledgment}

The authors would like to thank Family Medicine department affiliated to Faculty of Medicine, Suez Canal University, and all PHC physicians who accept to participate in this study.

\section{References}

1. World Health Organization (WHO). WHO traditional medicine strategy 2002-2005. Geneva, Switzerland. 2002.

2. World Health Organization (WHO). Traditional Medicine. Fact sheet no.134: 200812-01. (http://www.who.int/mediacentre /factsheets/fs134/en/index.html.) Retriev ed on 2009-05-02.

3. Abele J. Cupping a reliable alternative healing method. Germany (Eds.: Gustav F., Ulm Stuttgart J., Lubeck F).1998;p: 2224.

4. Yasin S. Cupping: a practice of prophet and a miraculous way of treatment. First edition.Egypt :Minhaj An-Nubuwwah Bookstore 2005,p:10-15.

5. Farhadi K, Schwebel DC, Saeb $M$, Choubsaz M, Mohammadi R, Ahmadi A. The effectiveness of wet-cupping for nonspecific low back pain in Iran: A randomized controlled trial. Complement Ther Med 2009; 17 (1): 9-15.

6. Wang SM, Peloquin C, Kain ZN. Attitudes of patients undergoing surgery toward alternative medical treatment. J Altern Complement Med 2002; 8(3): 351-356.

7. Chirali I. Z. Traditional, Chinese medicine, cupping therapy. Churchill Livingstone, London1999; P: 51-52, P: 69-85.

8. Morton M. Ten most commonly asked questions about alternative medicine. Alternative and complementary therapies1997. Available at Http//www. healthy.net/library/articles/morton/ten./h tm

9. Launiala A. How much can a KAP survey tell us about people's knowledge, atti- tudes, and practices? Some observations from medical anthropology research on malaria in pregnancy in Malawi. Anthropology Matters 2009; 11 (1).

10. Al SI, Ismail MF, Yousuf WA, Salama RE. Knowledge, attitudes and practice of general practitioners towards complementary and alternative medicine in Doha, Qatar. East Mediterr Health J. 2010; 16 (5): 522-527.

11. Sheiko M. Amazing Treatment, Syria,1999. Available at (http://www.thingsnotsaid.org/wavs/hijama.WMv

12. Complementary/alternative medicine: knowledge, attitudes and practice among general practitioners in Tehran, Iran Article 73, Volume 3, Supplement 2, Autumn 2004, Page 27-27.

13. El- mosalami D. Knowledge, attitude and practice of cupping (Hijama) among medical staff, 2006. Ph.D thesis, Cairo University.

14. Fadallah Kh., Prophete medicine in medication and treatment, Cupping Surgical Medicine. Egypt: Darketb Scientific Publishing and Distribution, 2004; p:84-90.

15. Hasan MY, Das M, Behjat S. Alternative medicine and the medical profession: views of medical students and general practitioners. East Mediterr Health J 2000; 6(1): 25-33.

16. Ahn AC, Ngo-Metzger Q, Legedza AT, Massagli MP, Clarridge BR, Phillips RS. Complementary and Alternative Medical Therapy Use among Chinese and Vietnamese Americans: Prevalence, Associated Factors, and Effects of PatientClinician Communication. Am J Public Health 2006; 96 (4): 647-653.

17. Cuellar N, Aycock T, Cahill B, Ford J. Complementary and alternative medicine (CAM) use by African American (AA) and Caucasian American (CA) older adults in a rural setting: a descriptive, comparative study. BMC Complement Altern Med 2003; 3:8.

18. Del Mundo WF, Shepherd WC, Marose TD. Use of alternative medicine by patients in a rural family practice clinic. Fam Med 2002; 34 (3): 206-212 
19. Honda K, Jacobson JS. Use of complementary and alternative medicine among United States adults: the influences of personality, coping strategies, and social support. Prev Med 2005; 40 (1):46-53.

20. WHO Regional Office for the Western Pacific. WHO Standard Acupuncture Point Locations in the Western Pacific Region. Manila: World Health Organization, 2008. (http://www.wpro.who.Int /publications/PUB_9789290613831/en/)

21. National center for complementary and alternative medicine (NCCAM): Complementary and alternative medicineUnited States 2005. (Http://nccam.nih. gov/health/whatiscam/

22. Shaikh BT, Hatcher J. Complementary and Alternative Medicine in Pakistan: Prospects and Limitations. Evid Based Complement Alternat Med. 2005; 2(2):139-142.

23. van Haselen RA, Reiber U, Nickel I, Jakob A, Fisher PA. Providing Complementary and Alternative Medicine in primary care: the primary care workers' perspective. Complement Ther. Med. 2004; 12(1): 6-16. 